\title{
CRISTINA PERI ROSSI. \\ ENTRETEJER VIDA Y LITERATURA, ANTE EL DESPOJO DEL TIEMPO ${ }^{1}$
}

\author{
POR \\ Meri Torras Francés \\ Universitat Autònoma de Barcelona
}

El tiempo todo lo transforma, todo lo pierde. Vivir es perder, despojarse.

Cristina Peri Rossi, "Detente, instante, eres tan bello"

A finales de 2015, por mediación de Cristina Peri Rossi, Jesús Gómez de Tejada me invitó a participar en un proyecto que estaba en ese momento forjando, un monográfico de la colección "Escritores del Cono Sur" dedicado íntegramente a la obra de esta autora uruguaya, que reside en España desde hace cuarenta y cinco años. Acepté agradecida y encantada, también algo espoleada por el reto que me lanzaba mi colega de la Universidad de Sevilla al poner bajo mi recaudo el análisis del (por entonces) último libro de Peri Rossi, el conjunto de relatos intitulado Los amores equivocados. La fecha de entrega era dilatada y me ofrecía tiempo suficiente para desempeñar mi tarea con el detenimiento y el cuidado requeridos, y en ello estaba cuando, el 8 de diciembre de 2016, recibí un correo electrónico de la propia Cristina Peri Rossi, con un adjunto bautizado como Sevilla1.doc y el siguiente incipit aclaratorio en el cuerpo del mensaje:

Querida Meri:

Te adjunto el extenso artículo autobiográfico que escribí para la Universidad de Sevilla. Posiblemente, sin ese volumen, jamás lo habría escrito, porque prefiero la imaginación a la biografía pura y dura, quizás porque me sé de memoria. Escribo para salir de mí, no para entrar, aunque mezcle ambas cosas. Pero después de haberlo escrito de un tirón me di cuenta de su importancia, de su calidez, de su sentido del humor a pesar de las dificultades y tragedias que cuento, y pienso que es un documento muy importante, y a la vez, imprescindible para cualquiera que desee conocer mi obra en profundidad. Confío en que te sea muy útil, que te diviertas a la vez que investigues y que sea una pieza antológica donde encontrarnos, doloridas y sonrientes, como debe ser. La vida

\footnotetext{
Este artículo se inscribe dentro del proyecto de investigación "La autoría en escena" (FFI2015-64978-P), financiado por el MINECO y vinculado al Grupo Investigador Consolidado Cuerpo y Textualidad, de la Universitat Autònoma de Barcelona.
} 
es una tragicomedia, no soy nada original al decirlo.

Todo lo que he escrito en ese texto es rigurosamente cierto. [...]

El sintagma "artículo autobiográfico" me chocó. En efecto, no hay prácticamente ningún texto anterior a este que Peri Rossi haya puesto en circulación bajo la clasificación de autobiografia; no se trata de una autora que nos haya contado $s u$ vida y, no obstante, hay una voz reconocible en sus textos que se le atribuye como propia. Cuando afirmo esto, no estoy ignorando las máscaras de distintos personajes que usa en los textos narrativos e incluso en algunos de sus poemas, ni me quiero referir exactamente a lo que podríamos denominar estilo; más precisamente aludo a una persona-personaje que atraviesa los distintos textos rubricados por Peri Rossi y que podemos reconocer en los diversos géneros literarios practicados por esta autora (poesía, narrativa, artículos de prensa, entradas del blog...). Dicho de otro modo, la imagen de autora que se desprende del conjunto de la obra de Peri Rossi es profundamente vívida, carnal, y a pesar de su larga trayectoria como una escritora ciertamente prolífica, me atrevería a decir que su autora implícita o implicada, en el sentido del término acuñado por Wayne Booth, se nos antoja como alguien muy lúcido y coherente, que integra sus transformaciones en el curso de los años, ama, encuentra, pierde, enferma, envejece y agudiza aún más su ironía. Todo ello apelando a la complicidad imprescindible de quien la lee. En el fragmento de correo electrónico citado más arriba, la propia autora confiesa que habitualmente mezcla imaginación y biografia en la escritura; sin embargo, ¿cómo diferenciar?, ¿cómo saber qué pertenece a uno u otro reino?, ¿es este deslinde lo que debemos proponernos ante un texto perirrossiano de factura autos-autor? A mi modo de ver, la respuesta es no. Su obra permite otro modo de interacción mucho más atractivo que el rastreo de lo documentable como facto.

El propósito de este artículo es reflexionar sobre los procedimientos que sigue Cristina Peri Rossi para contribuir a construir textualmente una imagen de sí; el modo en que algunos de sus textos han sido porosos al calado de la propia vida, empezando por este texto autobiográfico que aparece en el monográfico de "Escritores del Cono Sur". De este modo, el artículo autobiográfico "Detente, instante, eres tan bello" constituye el objeto fundamental de este análisis, su principio y su fin, que se aborda a partir de tres ejes interrelacionados que, a su vez, sirven para establecer conexiones con otros textos y otros ámbitos de la producción autoral de la escritora uruguaya, a fin de mostrar un diálogo radial que desde esta fuente implica textos precedentes, los enreda desde esa red intertextual que sostiene su cuerpo-corpus literario.

EL GÉNERO TEXTUAL: VIDA Y LITERATURA

En primer lugar, el estudio de esta contribución de Peri Rossi ahondará en su género textual, puesto que este constituye la clave de lectura: ¿cuándo?, ¿cómo? y ¿dónde?

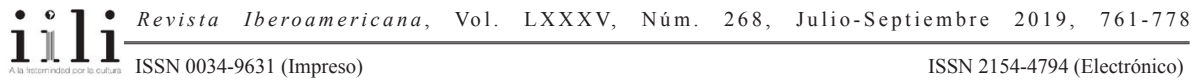


se han encontrado formalmente vida y literatura. ¿Qué protocolos de lectura impone este encuentro dentro de la tradición occidental? ¿En cuáles de estos espejos se mira el texto perirrossiano? ¿En qué grado los reproduce y hasta qué punto los transforma en la concreción que nos ofrece? Advertencia de la autora uruguaya en el correo que acompaña al texto: no se trata de "biografía pura y dura". Detalle: aunque en el cuerpo del correo lo ha denominado artículo autobiográfico, a renglón seguido Peri Rossi no escribe autobiografía, sino biografía, borrando de un plumazo el autos o, lo que es lo mismo, la mirada del texto sobre sí misma desde sí misma. El binomio que acaba dibujando es el de imaginación versus biografía, un dualismo que invoca una jerarquía propicia para la ficción que estaría, lógicamente, del lado del primer término, mientras que la opción biográfica implicaría hablar de sí mismo como de una tercera persona y con valor factual.

La mutación es sutil pero significativa: no se trata de crear personajes que se le parezcan, que documenten el acontecer de su existencia y/o su manera de ser y sentir (que podría ser una de las materializaciones de la opción biografía). Frente a eso, Peri Rossi se inscribe en una línea de autores que reclaman el derecho de inventarse a sí mismos como autores y a través de su obra en diálogo con la literatura, sin que por ello lo que se cuente deje de ser "rigurosamente cierto" (opción imaginación). Por un lado, eso acontece casi como una consecuencia insoslayable del funcionamiento de la memoria: "Toda memoria es mala memoria, por eso, escribo, víctima de la fugacidad" (Peri Rossi, "Detente, instante” 26), confesará más adelante. ${ }^{2}$ Por otro lado, cabe añadir que ficcionalizarse es un derecho que el autor-creador puede ejercer y que en las últimas décadas está incluso reivindicado: en este sentido podría entenderse la emergencia y consolidación de la autoficción (del término y sus deslindes teóricos, ya que, por lo que el concepto conlleva, tengo la impresión que se viene practicando desde siempre), ${ }^{3}$ que

2 En este sentido se asoma y reivindica aquí su sentir de poeta, al menos a mi juicio. No puedo dejar de poner en relación esta afirmación con la llamada poesía de la experiencia y su productiva relación con la memoria, puesta en práctica en su vertiente barcelonesa, por dos extraordinarios poetas: Jaime Gil de Biedma y Gabriel Ferrater, que eligieron cada uno una lengua (y un objeto-sujeto de deseo amorososexual también distinto), pero entre quienes puede establecerse vínculos no solo personales de amistad (compartida con Carlos Barral y José Agustín Goytisolo), sino sobre todo creativos. Remarcable es, sin duda, en este orden de cosas, la poética del recuerdo, el olvido y la invención que plantea el propio Carlos Barral en sus volúmenes de memorias. Remito a los múltiples trabajos de Carme Riera a propósito de la denominada Escuela de Barcelona, un grupo de autores que Peri Rossi conoció y leyó.

3 A fin de que se entienda a lo que me refiero, ¿practican autoficción Sor Juana Inés de la Cruz y el Obispo de Puebla en su intercambio epistolar, travestido este en Sor Filotea de la Cruz? Lo que cuenta Juana de Asbaje en su respuesta, ¿pretende ser la pura transcripción neutra de lo acontecido en su vida o una intensa estrategia retórica para defender su derecho a pensar y escribir también sobre temas religiosos? Otro ejemplo: ¿Se sincera Gertrudis Gómez de Avellaneda en su carta "Cuadernillo”, dirigida a Ignacio de Cepeda? ¿Le cuenta su vida a pecho descubierto, o más bien trata de justificar a través del relato su (mala) fama con los hombres para conseguir que Cepeda se deje seducir y atienda de una vez su reclamo

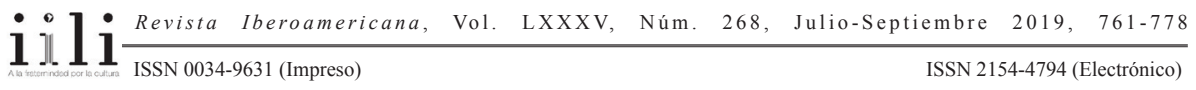


en un momento determinado -hacia el último cuarto del siglo XX y desde el territorio de la escritura literaria- inscribe en el panorama de los estudios literarios un tour de force muy sugerente frente a la exigencia de veracidad de la autobiografía, la muerte del autor barthesiana o la dimensión ética de la literatura, por citar tres cuestiones que entre tantas otras han cruzado el pensamiento literario contemporáneo. ${ }^{4}$

Retomemos, por orden, estas dos opciones que acabamos de deslindar, a partir de las palabras de la autora. Entre sus obras, Peri Rossi cuenta con una biografia que ha sufrido, precisamente, la operación contraria a la que ella misma incurre en el correo personal ya citado; es decir, una biografía que recuperó el autos y se convirtió en autobiografía, en una transformación muy interesante que está directamente relacionada con los procesos de autor-representación que nos ocupan en este monográfico. Me refiero al volumen Julio Cortázar, aparecido en 2001 en la editorial Omega, concretamente en la colección "Vidas literarias", dirigida por Nuria Amat. Recientemente, en 2014, la editorial Cálamo publicó otro primer texto autobiográfico de Peri Rossi (ya se verá que tiene varios primeros textos autobiográficos): ${ }^{5}$ me refiero al que dedica a su relación personal y literaria con este autor argentino, bajo el título de Julio Cortázar y Cris. ${ }^{6}$ Este volumen autobiográfico se basa en el texto precedente, la biografía publicada trece años antes. Ambos libros no son exactamente iguales; comparten unas ochenta páginas idénticas que, en la edición de Omega, vienen acompañadas de una selección de la obra del autor argentino antologada por la propia Peri Rossi. En la nueva edición de Cálamo, la segunda parte son piezas de factura varia, algunas cartas, otros textos de homenaje a Cortázar escritos tras su muerte por la autora. Los paratextos son suficientemente elocuentes de la transformación de un (casi pero ya no) mismo texto. Julio Cortázar, una biografía, Julio Cortázar y Cris, una autobiografía. "Cris" aparece en el título de la segunda edición al mismo tiempo que el autos en las consideraciones de género; pero ambos estaban ya bajo la forma de biografía y el título sucinto de la primera. Los

amoroso-sexual? Y una incursión contemporánea: ¿Qué género practica Silvina Ocampo cuando, frente a los copiosos volúmenes autobiográficos de su hermana Victoria, ella escribe su autobiografía (¿autoficción?) en un breve texto titulado Invenciones del recuerdo, que recoge el período de sus cinco primeros años de vida, donde -advierte la argentina, esposa de Bioy Casares, amiga de Borges...- está todo? Estos casos, que conozco con profundidad, señalan el carácter ficcional de la autobiografía y allanan el camino que la acerca como género a la fabulación. Y, no menos relevante, de ellos surgen interrogantes a propósito de la posición de (en este caso) las autoras en relación a la diégesis. Véase Torras (Soy como consiga y "La invención de").

4 Remito al texto "El simulacro del yo: la autoficción en la narrativa actual", que Ana Casas elaboró para introducir la selección de artículos teóricos que ella misma compiló para un volumen a todas luces imprescindible, La autoficción. Reflexiones teóricas, aparecido en 2012.

5 Así consta claramente en la contraportada: Julio Cortázar y Cris se define como la "[p]rimera pieza autobiográfica de una de las autoras más consagradas de la literatura hispanoamericana”.

6 Hemos trabajado este texto en Moszczynska-Dürst y Torras. 
límites entre ambos géneros son tan difusos como lo son, en el texto, los límites entre ambos escritores ficcionalizados.

El "Cris", apelativo con que un consagrado Cortázar se refería cariñosamente a su joven colega y amiga uruguaya, evidencia este reconocimiento mutuo y pone de manifiesto el lugar desde donde se enuncia el discurso sobre el autor argentino, desde la voz de Peri Rossi y en relación con ella. Por todo eso, "Cris" no disminuye la consideración que merece la autora en el texto, sino todo lo contrario, ella y Cortázar se presentan como semblables, frères et sœurs, inseparables. Peri Rossi despliega un juego literario a través de la misma literatura, ${ }^{7}$ se dirige a un tú que se identifica como Cortázar y a través de la escritura deja huella deformada (el texto escrito, con su dosis de ficción, al hilo del recuerdo) de lo informe (el pasado, tanta vida compartida ya irrecuperable, la propia presencia de Julio Cortázar):

A medida que voy escribiendo este libro, que no pensaba escribir nunca, siento que el tiempo real es el pasado, el tiempo inmediato es el pasado, y cuando paro a descansar un poco -ya no fumo, Julio, ni siquiera el cigarrillo de después de hacer el amor, qué combate, al fin dejar de fumar fue como exiliarse de la nicotina, como tu muerte fue exiliarme de París y hasta de cierta manera de estar en Barcelona-me siento extraña, el miedo a no volver que nos asalta a los escritores, el miedo a quedarse en aquellas provincias inventadas, en la memoria que es un poco invención y un poco fantasía, pero si es lo único que nos queda de tantas palabras, de tantos paseos, de tanta vida. (Peri Rossi, Julio Cortázar y Cris 53)

El devenir de sus textos sobre Cortázar son una muestra, pues, de cómo la literatura se apodera de todo, no hay nada que le sea ajeno, en el territorio perirrosiano. Lo que se le encargó como biografía se empapa de un yo-Cris(tina Peri Rossi)-que introduce indefectiblemente un punto de vista que es indisociable de un modo de leer la vida como escritora, esto es, en clave de literatura o enclave de literatura, en cualquier caso vida y literatura discurren de forma inseparable.

A mí, sabiéndome ya seducida por su obra, en su correo del 8 de diciembre de 2016, Cristina Peri Rossi también me provoca y convoca a encontrarlo todo, a encontrarnos a nosotras mismas en el texto, doloridas y sonrientes, como debe ser. Esa dualidad paradójica obedece al género no del texto, sino de la vida misma, una tragicomedia, afirma, y alude a su escasa originalidad por decirlo. El gesto no me parece gratuito y quiero detenerme en él. La tragicomedia es un género teatral, que

7 De la literatura como escritura, en unos derroteros explícitamente deconstruccionistas, pero también desde la propia literatura cortazariana; por ejemplo, con el uso y la interpretación que nos brinda del cuento "Diario de un cuento", que tematiza y despliega la imposibilidad de hacer presente lo ausente, Anabel en el cuento, el propio Cortázar o ella misma Cris, pero ya no más Cris o ya no solamente Cris, ni mucho menos esa Cris...

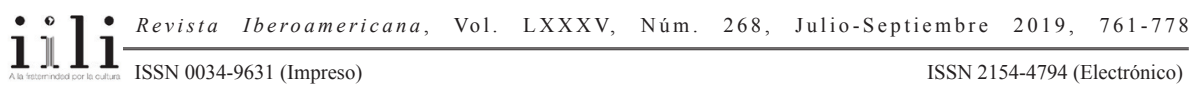


retoma con determinadas particularidades la tragicomedia griega clásica, y que en la tradición hispánica se considera que fue fundado por La Celestina. Por lo que a mí me interesa ahora, Peri Rossi se sirve de un género ficcional para caracterizar no el texto autobiográfico que me manda, sino -insisto- la vida. Así pues, damos de pleno en esa constante que acabo de señalar en la obra de esta escritora: vida y literatura son indiferenciables (esa mezcla a la que ella misma alude y que sin duda atraviesa toda su obra); más aún, puesta a dar sentido a su vida, y ante el despojo implacable del tiempo, Peri Rossi la entiende por la literatura, como literatura.

No es, pues, esta escritora alguien excesivamente preocupada en acatar la ley del género que rige la lógica de pureza y prohíbe la mezcla y la (con)fusión. ${ }^{8}$ Autoconsciente de su querencia y no sin ironía, en "Detente, instante, eres tan bello" afirma:

Lo cierto es que a los críticos y a los libreros no les gusta una escritora poeta, narradora y ensayista. Deslizan subrepticiamente la sospecha de que quizás es porque no se siente plenamente realizada en ningún género, lo cual es una mezquindad difícil de admitir. ¿Cómo se clasifica a una escritora así? Bueno, ¿y por qué no dejamos de lado las clasificaciones? Escribo con mis voces, no con mi voz, y si mezclo géneros y a veces soy muy lírica en novela y muy narrativa en un poema es justamente para afirmar la libertad del arte, al cual no conviene ponerle moldes. El arte, por suerte, no es normativo. (29)

Si, por otro lado, seguimos el hilo de la imaginación, que Peri Rossi oponía a la biografía, ${ }^{9}$ el que sitúa sin ambages la ficción en el centro, se puede plantear si no estamos ante una obra que coquetea con la autoficción; es decir, que gusta de colocarse en un terreno fronterizo entre invención y facticidad, confundiendo ambos ámbitos deliberadamente. ${ }^{10}$ Es cierto, además, que la ironía de Peri Rossi contribuye a la sensación lúdica que escritoras como Delphine De Vigan o Stéphanie Hochet prefieren para la autoficción (frente a las acusaciones de falta de seriedad de esta factura literaria), ${ }^{11}$

8 Tomo prestado el sintagma del magnífico artículo de Jacques Derrida "The Law of Genre”, por el que descubrimos, entre otras muchas cosas, que la ley de la pureza que rige los géneros textuales (y no solo textuales) implica una contra ley, que señala precisamente la capacidad de mezclarse que estos poseen. Derrida apuesta por una relación de participación (no de pertenencia) de un texto a un género, de modo que un mismo texto puede participar de diversos géneros, justamente por su poder (inter)textual.

9 Después de analizar el caso de Julio Cortázar y Julio Cortázar y Cris se puede sostener que se trata de una disyuntiva falsa, puesto que la propia Peri Rossi ha llevado a cabo una biografía (auto)ficcional, y no por ello menos verdadera, de su amado y admirado autor argentino.

10 Remito a la idea de "pacto ambiguo" que parte, sobre todo, de Manuel Alberca. Remito a su conocido ensayo intitulado precisamente El pacto ambiguo. De la novela autobiográfica a la autoficción. La idea ya se apuntaba en Fiction et diction (1991), de Gerard Genette, con esa modelización como mínimo paradójica de "C'est moi et ce n'est pas moi" (Genette 161).

11 Cito estas dos autoras francesas que, recientemente, han propuesto juegos autoficcionales: Delphine de Vigan, a través de un juego de dobles y/o de desdoblamientos con D'après une histoire vrai (2015), 
distinción que se ajusta a medida de la obra de la escritora uruguaya, una literatura que nos invita a sonreír pero que sin duda es seria y rigurosa, cuya voz no tiembla al denunciar cuestiones menos amables, incluso de su propio oficio y condición de autora consagrada:

La pobreza que había pasado en la infancia y en la juventud me han acompañado siempre y ante los seres normales (los que no escriben) constituye un enigma: creen que con el buen número de libros publicados ya debería haber salido de ella. Nunca he deseado ser rica, no ha sido mi sueño, pero es verdad que la inseguridad económica, la incertidumbre son fardos pesados y lastran la vida cotidiana. Por lo menos dos veces rechacé premios literarios de narrativa muy importantes y muy bien dotados por no aceptar modificaciones en el texto original. Es posible que cualquier día me arrepienta, especialmente ahora, en la vejez. (Peri Rossi, "Detente, instante" 34; cursivas del original)

La autor-representación de Peri Rossi puede leerse con esa dosis de representación teatral que, según parece, requiere el género de la autoficción: "Un personaje ficticio [...] se disfraza (continuamente en grandes partes del texto) con el nombre o un derivado del autor real y/o con características biográficas similares" (Toro, Schlickers y Luengo 21).

No obstante, al hilo de lo que el presunto texto autobiográfico publicado en la antología crítica coordinada por Gómez de Tejada sugiere, mi consideración sobre las estrategias de Cristina Peri Rossi para autor-representarse rehúyen irrupciones abruptas y sorpresivas, así como disfraces varios a través de sus personajes, y abrazan fórmulas aparentemente más clásicas. A mi entender, la estrategia perirrosiana se asemeja más al fingimiento que formulara Fernando de Pessoa, ${ }^{12}$ derivado del mismo medio donde

cuya protagonista es una escritora llamada Delphine que trata de volver a escribir tras el éxito de Rien ne s'oppose à la nuit; y Stéphanie Hochet, más explícitamente irónica con L'animal et son biographe (2017), protagonizada por una escritora urbana y capitalina, que se parece mucho a ella, fuera de su medio. Ambos textos invitan a reflexionar a propósito de la relación de la literatura con la realidad, de los límites entre facticidad y ficción, y -a mi juicio-, con estilos muy distintos, teorizan a propósito del lugar del autor y su relación no solo con el público sino con el mundo. Peri Rossi no dota ninguna de sus obras con un juego autoficcional tan manifiesto; no obstante, la reflexión y el posicionamiento respecto a estas cuestiones cruza su producción y constituye no solamente su poética, sino su yo-autora implícita Cristina Peri Rossi. En otro orden de cosas, cuando afirmo que la autoficción ha sido tildada de "género poco serio", me refiero al título elegido por Marie Darrieussecq para su artículo aparecido en Poétique, en 1996: "L'autofiction: un genre pas sérieux".

12 Huelga decir que me refiero a su archiconocido poema: "O poeta é um fingidor. / Finge tão completamente / Que chega a fingir que é dor / A dor que deveras sente". Hay dos estrofas más, menos conocidas y, en su formulación, menos impactantes. La segunda, precisamente, se refiere a lo que sienten los lectores del poema, que no es el dolor del poeta sino el dolor que no consiguen tener. Una cuestión nada ajena a lo que recorre este artículo, el mismo motivo que recoge la autora en uno de sus poemarios más logrados, Lingüistica general (1979), cuando apunta: "Escribo porque olvido / y alguien lee porque no evoca de manera / suficiente" (373).

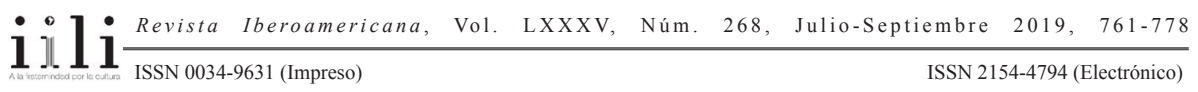


respira unx autorx, especialmente unx poeta: el lenguaje. Además, sin poder esgrimir argumentos definitivos que invaliden la lectura autoficcional (al contrario, creo que ella es completamente posible), mi apuesta interpretativa se desarrolla en la encrucijada de la retórica y la ética, y recurriré al concepto de autor implícito o implicado, que acuñara Wayne C. Booth en 1961, en su ensayo -ya clásico-The Rhetoric of Fiction. La inflexión que supuso este ensayo consistió mayormente en un cambio de foco hacia la dimensión retórica de las técnicas narrativas en relación, sobre todo, con el vínculo que establecen con el público lector implícito desde una dimensión ética. ${ }^{13}$

Alo largo de su dilatada trayectoria como escritora, Cristina Peri Rossi ha convivido con una autora implicada que no le es ajena. Por un lado, porque ella (y, hasta cierto punto, tiene agencia para ello) la ha construido, paulatinamente, a partir de su obra y de esos espacios inter y paratextuales de presencia y enunciación pública (contraportadas, entrevistas, fotografías, artículos periodísticos, conferencias, clases, blog personal...), que constituyen su capital de visibilidad. ${ }^{14}$ Por otro lado, Peri Rossi ha mantenido con esta autora implicada una relación de (sorprendente) fidelidad; sus distintas voces son armoniosas y sintonizan con la imagen de sí que se desprende del conjunto de su obra. Así, en "Detente, instante, eres tan bello" es reconocible quien habla, por este fenómeno de coherencia retórica que trasciende, entonces, la consideración de género textual y permea otros ejes sobre los que vamos a reflexionar en los apartados que siguen.

\section{EL TÍTULO: UNA POÉTICA}

El manuscrito, por llamarlo con un nombre inexacto pero apropiado, que me llegó adjunto en el fichero Sevilla1.doc, contaba con poco más de veinte páginas, estaba fechado en mayo de 2016 y se titulaba, como ya se ha apuntado, "Detente, instante, eres tan bello". El mefistofélico título no hace sino enfatizar la pinza que refería más arriba entre vida y literatura. Proviene precisamente de la literatura, en concreto de Fausto, pero las palabras del personaje de Goethe llegan al texto de nuestra escritora mediatizadas por la propia voz de la autora. En realidad, Peri Rossi se cita (también) a sí misma: de entrada, alude a la poética que escribió por encargo de Víctor Pozanco, para la antología Nueve poetas del resurgimiento, aparecida en Barcelona, en 1976.

13 En efecto, con este ensayo, Booth abre camino a lo que posteriormente se denominó el giró ético en la teoría y la crítica literarias, que se consolidó a lo largo de la segunda mitad de la década de los ochenta y principios de los noventa, con textos como The Company We Keep. An Ethics of Fiction (1988), del propio Booth; o The Ethics of Reading (1989), de J. Hillis Miller; y Love's Knowledge (1990), de Martha Nussbaum, por citar algunos de los títulos más conocidos.

14 Nathalie Heinich propone este término para hacer referencia a la mise en présence de lxs artistas en general, entre ellxs lxs autorxs: "[L]a primera y fundamental dimensión que funda el fenómeno de la visibilidad en el mundo contemporáneo [es] la reproducción técnica de rostros a gran escala generadora de una búsqueda de puesta en presencia con el original -búsqueda constitutiva del valor de autenticidad" (32).

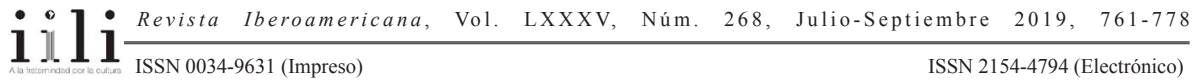


[...] escribo por amor a las palabras y a las emociones, a todo aquello que con el tiempo será mala memoria y fugacidad. Escribo para guardar y conservar el instante vanidoso y pasajero, contra la muerte. Y para inventar lo que no existe (razón suficiente para ser inventado) y testimoniar lo que existiendo, pronto dejará de ser. Escribo porque el tiempo todo lo cambia. Al testimoniar las cosas las modifico, recreándolas, y en esa dulce ocupación de gozar, sentir, apreciar formas, colores, texturas, gestos, paisajes, ideas y fijarlas en la escritura - para que no desaparezcan-siento que participo, humildemente, en la creación. Pienso, entonces, que escribo porque me muero, porque todo transcurre rápidamente y a veces experimento el deseo de retenerlo; la literatura es testimonio precisamente porque todo está condenado a desaparecer, y eso nos conmueve, nos pide a gritos residencia [...]. (25-26)

Tras exponer las razones por las que escribe, Peri Rossi culmina esta hermosa enumeración con la consabida cita.

Escribir para burlar la muerte, para luchar contra la desaparición de las cosas que nos tocan, para detener el tiempo en el instante precioso y preciso. La idea ha surgido en la declaración de una poética, al inicio de su devenir escritora, y reaparece cuatro décadas después dando título a un texto sobre su vida. Pero no son esas las dos únicas ocasiones en las que la autora recurre a esta formulación goethiana. En su artículo autobiográfico, publicado en 2017, Peri Rossi sella la vigencia de esta confesión con una nueva autocita, esta vez de uno de sus poemarios más recientes, La noche y su artificio, aparecido en 2014, cuyo décimo poema se titula precisamente "Detente, instante, eres tan bello" y empieza así:

Como el joven Fausto seducido por Mefistófeles
al inclinarme sobre tu cuerpo
al besar tu sonrisa
al encender tus senos como faros de Alejandría
dije: "Detente, instante, eres tan bello"
y todo en mí era una ola
precipitándose sobre el tiempo [...]. (23)

Además, cabe añadir que la frase de Fausto había aparecido ya en un poema anterior a este, uno que ella no cita, intitulado "Asombro" y perteneciente a Habitación de hotel (2007).

Enséñame -dices, desde tus veintiún años

ávidos, creyendo, todavía, que se puede enseñar alguna cosa

y yo, que pasé de los sesenta

te miro con amor

es decir, con lejanía

(todo amor es amor a las diferencias

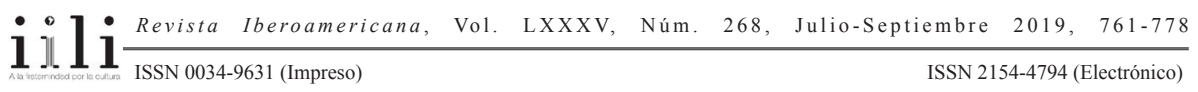


al espacio vacío entre dos cuerpos

al espacio vacío entre dos mentes

al horrible presentimiento de no morir de a dos)

te enseño, mansamente, alguna cita de Goethe

("detente, instante, eres tan bello")

o de Kafka (una vez hubo, hubo una vez

una sirena que no cantó)

mientras la noche lentamente se desliza hacia el alba [...]. (73)

A estas alturas, la frase es más de Peri Rossi que del propio Goethe; se trata, con toda probabilidad, de una conjuración replicante, en el sentido que ella otorga a su último poemario Las replicantes (pero en el que insiste de algún modo en su posterior antología de cuentos Los amores equivocados); ${ }^{15}$ esto es, aquello que regresa en forma de fetiche-revenante e impregna de presencias vitales y poéticas este corpus-texto que, a modo casi de fórmula mágica, lo convoca todo: lo que la escritura ofrece a la vida (el reto de la imposibilidad de detener el tiempo), lo que la vida ofrece a la escritura (el acicate de la certeza de lo fugaz): "Mientras escribo estas líneas soy feliz, pero lo dejaré de ser en cuanto me detenga, no hay manera de retener lo efímero, lo pasajero. Y la vida es eso, fugacidad" ("Detente, instante" 24).

Tras explicar qué son las efímeras y su pasión por reproducirse y poner huevos durante el brevísimo tiempo que tienen de vida, añade: “¿Serán el arte, los libros, las músicas, las películas, la arquitectura, los dibujos en las cavernas, los grafitis, los versos en Internet, la fotografía, la ciencia y la técnica los huevos que nosotros, hombres o mujeres, depositamos antes de morir?" ("Detente, instante” 25).

Esa es la clave que inscribe el paratexto del título: una poética de vida pero, al mismo tiempo, la poética de su escritura. Por todo ello, por la memoria intertextual que elige en el título para su artículo autobiográfico, de nuevo, como tantas veces, vida y obra devienen indiferenciables y, en consecuencia, Peri Rossi y su obra, también: es la poética de la vida y de la obra de la escritora Cristina Peri Rossi. La posición que se otorga la autora no es la de precedencia sino la de simultaneidad con los textos producidos. Todos son uno y el mismo, todos están (y ya no están) aquí, detenidos en el instante de la palabra cuando alguien -lectorx- lee "detente, instante, eres tan bello". Y el instante, inmediatamente, ya pasó.

En definitiva, a mi juicio, para Peri Rossi la escritura es la memoria encarnada en el lenguaje, pero no la memoria del listado, de la relación ordenada o de los anales,

15 Remito a mi artículo "Trabajos de amor (re)vividos. Afectos y efectos en Los amores equivocados (2015)”, en Jesús Gómez de Tejada (coord.).

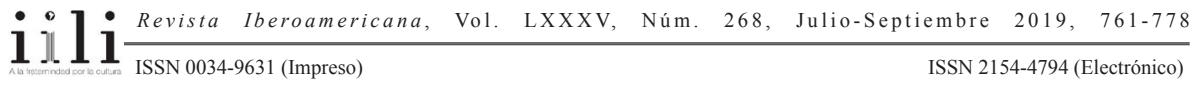


la memoria se encarna precisamente a través de un cuerpo-corpus (obra) de un yo que filtra, un sujeto por siempre sujeto al texto que lo constituye (la autora implícita):

[...] la diferencia fundamental entre la vida y el arte es la capacidad de seleccionar, o sea, de elegir, igual que en el amor. Para amar, elegimos, por más instintiva, irracional e inconsciente que sea la elección de objeto (es una bendición: si la elección fuera racional, solo algunos objetos recibirían nuestro amor) y para pintar, poetizar, relatar, hacer música, fotografiar, también seleccionamos, aunque la clave de esta selección sea completamente subjetiva [...]. ("Detente, instante" 27)

Con la escritura, la autora implícita inscribe la muerte, la separación, la desaparición, al mismo tiempo que se resiste a ellas. "El poeta no escribe sobre las cosas, / sino sobre el nombre de las cosas" (Poesía 369), con este dístico se inaugura Lingüística general (1979). Las palabras no son las cosas, aunque median necesariamente en nuestra relación con la realidad, la re-presentan y con ello le otorgan un carácter fantasmal de una presencia ausente. "Escribimos porque los objetos de los que queremos hablar no están” (Poesía 374).

En "Detente, instante, eres tan bello", Peri Rossi hace referencia a una narración suya de juventud que ha permanecido inédita, cuya trama versa a propósito de un científico que se inserta una célula, una especie de chip, que le permite filmar toda su vida las veinticuatro horas del día. Esa obsesión por reproducir cada instante al que lo obliga la máquina implantada en el cerebro lo lleva a la locura y hasta al suicidio "por un empacho de realidad", concluye Peri Rossi. El relato aludido nos remite tanto a "Funes el memorioso" o a "Del rigor en la ciencia" borgianos, como al capítulo tercero de la primera temporada de Black Mirror. Recordarlo todo tal y como fue, con todo lujo de detalles, es insoportable, invivible, hay que seleccionar y hay que olvidar, deformar, desmemoriarse...

Yo no quiero recordarlo todo, sino ese instante de plenitud, de éxtasis sensorial o imaginativo en que rocé la eternidad, en que tuve un atisbo de inmortalidad. Para retenerlo empleo la cámara fotográfica, escribo el poema, grabo la música... pero indefectiblemente, con el paso del tiempo, la intensidad de la emoción desaparece, condenada a repetirla en la vida o dejarla morir. ("Detente, instante" 27)

Como desarrolla en su poema "Mi casa es la escritura", recogido en Habitación de hotel (2007), la escritura deviene para Peri Rossi una máquina de tiempo detenido $\mathrm{y}$, sobre todo, su casa, el lugar donde habita, donde es:

$[\ldots]$

No me creció una planta

no me creció un perro

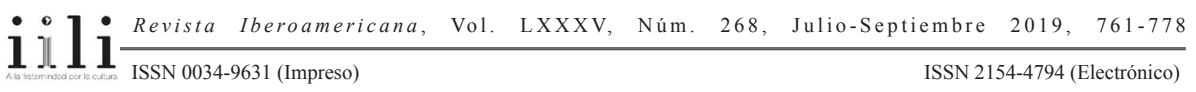




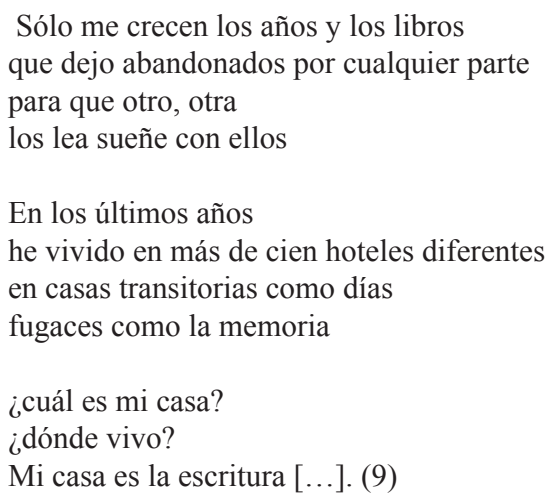

El tránsito, ya no solo considerado desde un punto de vista temporal, como se ha analizado en este segundo apartado, sino abarcando también el espacio, así como experiencias vitales fundamentales como el placer, el amor y la (futura) muerte, es el tercer eje que propongo en el rastreo de esta autora implícita, en el territorio de lindes cada vez más difuminadas de este primer artículo autobiográfico.

\section{EL TRÁNSITO: NAVEGACIONES, EXILIOS Y NAUFRAGIOS}

"Detente, instante, eres tan bello" se inicia a partir de su precipitada huida de Montevideo: "Tuve veinticuatro horas para exiliarme, yo, que no había viajado nunca [...] y que imaginaba mi vida entera en Montevideo: como Julio Verne, pensaba que a una escritora le bastaba con lo que sentía y con lo que imaginaba" ("Detente, instante" 21).

Es 1972, exactamente el 4 de octubre. Peri Rossi se lleva su máquina de escribir Remington, cientos de folios color cebolla y un ejemplar de cada uno de los libros que ha publicado hasta entonces, cinco en total: Viviendo (1963), Los museos abandonados (1969), El libro de mis primos (1969), Indicios pánicos (1970) y Evohé (1971). Se lleva también un poemario inédito, Descripción de un naufragio. Nada más. Ligera de equipaje, se planta en la España franquista. La propia autora ironiza sobre su elección:

Aparentemente es paradójico que alguien se exilie de una dictadura en otra, pero cuando uno se exilia como yo, en veinticuatro horas, no tiene una guía turística a su disposición para elegir a qué ciudad desea ir. Uno no se va: lo echan y se escapa adonde puede, no adonde quiere. Los filósofos pesimistas griegos tenían una sentencia: "Lo mejor es no nacer. Pero en caso de nacer, lo mejor es no ser exiliado". Sabían de lo que hablaban. [...] Suelo decir que tuve la desgracia de vivir el ascenso del fascismo en mi país natal y la dicha de verlo caer en el país de adopción y como soy cosmopolita y renacentista, me parece que la experiencia vale igual que si solo lo hubiera visto en el mismo sitio. ("Detente, instante" 21) 
El exilio es una experiencia traumática, un desplazamiento impuesto que inscribe para siempre el trazo de la pérdida en el devenir de la persona exiliada, que no podrá volver nunca allí de donde fue expulsada, ni aún volviendo. Inmediatamente veremos cómo el tránsito del exilio, con lo que conlleva de dolor y pérdida, pero también de enriquecimiento y hallazgo, se acerca desde la articulación que propone Cristina Peri Rossi, a la vivencia del amor. A lo largo de este tercer eje, se irá desbrozando el ensamblaje de estas experiencias a fin de señalar cómo en la idea de tránsito - la escritura misma lo es, una sucesión, un devenir - se imprime esa voz distintiva y reconocible de la autora implícita Cristina Peri Rossi.

En una entrevista realizada por Gabriela Trevisán en abril de 2010, con motivo de la traducción al inglés del poemario Estado de exilio (2003), ${ }^{16}$ Cristina Peri Rossi ya había puntualizado que la experiencia del exilio es distinta a la de la migración:

Es cierto que exilio y emigración tienen muchísimos puntos en común. A veces converso con emigrantes y observo los sentimientos compartidos: el desarraigo, la sensación de no pertenencia, la ambigüedad en cuanto al país de adopción; sin embargo, están en mejores condiciones objetivas: ahora tienen móviles para llamar a sus seres queridos, se pueden reunir públicamente sin despertar sospechas, pueden obtener la residencia o la nacionalidad. Los emigrantes tienen una ilusión: volver. Pueden ejercer esa facultad. El exiliado no puede volver, y esto le causa mucha angustia. Ahora bien, una vez caída la dictadura, no siempre el exiliado vuelve. Porque en un sentido estricto, no hay regreso: no se puede volver al pasado. (Peri Rossi en Trevisán s/p)

En el texto para el volumen de la Universidad de Sevilla, Peri Rossi retoma esta cuestión e insiste en esta diferencia a todas luces crucial, para reformularla precisamente en clave amorosa: ${ }^{17}$

Las parejas no suelen sobrevivir al exilio, al revés de los emigrantes. Porque los exiliados han perdido una guerra, han fracasado, en cambio, los emigrantes, tienen una ilusión: vivir mejor allí donde se establecen. Al exiliarme, yo no tenía ninguna ilusión, más que la de regresar lo antes posible y recuperar mi vida montevideana: dar clases de literatura, ver todas las películas, leer todos los libros, escuchar toda la música, conversar con mis amigos y caminar por las calles de Montevideo, llenas de secretos, de quintas misteriosas, de personajes extravagantes y de una generación que quiso

${ }_{16}$ La traducción del poemario al inglés se realiza treinta años después. Los poemas de Estado de exilio remiten a sus primeros años en Barcelona, tras haber tenido que salir apresuradamente de Montevideo.

17 Esta diferencia cruza también alguno de sus relatos; por ejemplo, en "Los amores equivocados", del volumen homónimo aparecido en 2015, donde aventuro podemos entender que la pareja protagonista siente cada unx más cerca de uno de estos polos. Es una conjetura que desarrollo parcialmente en Torras ("Trabajos de amor").

$1] 1$ Revista Iberoamericana, Vol. LXXXV, Núm. 268, Julio-Septiembre 2019, $761-778$ 
cambiar el mundo a imagen de sus sueños. Y para volver a conversar. Al exiliarme, perdí la conversación, esa suerte de religión montevideana. ("Detente, instante" 23)

El exilio se aúna con el amor a través del tránsito y de la pérdida. Un tránsito inevitable y una pérdida a veces necesaria, otras irreparable, otras hasta sumida en el pozo sin fondo de la desmemoria, capaz de volver a emerger de repente con la cicatriz de un dolor intacto por lo que fue y ya no es, ya no puede ser. Un poema de Elizabeth Bishop sirve a Peri Rossi para subrayar el nexo: se trata del conocido "One art", destinado a "the art of losing", un texto con una voz distanciada, hasta irónica a veces, a pesar de lo mucho que Bishop perdió. ${ }^{18}$ Por si el nexo no quedara lo suficientemente claro, sentencia Peri Rossi: "Los exilios son experiencias muy dolorosas y a la vez, muy enriquecedoras, como el amor" ("Detente, instante" 24). El símil no es nuevo, ni en la historia de las ideas y de los imaginarios occidentales, ni tampoco en el conjunto de la dilatada obra de esta autora. Los modelos de relación amorosa-sexual que construye la escritora a lo largo de sus textos tienen que ver con la idea de tránsito, con el arte de navegar. Así, por ejemplo, como botón de muestra, el poema "Navegación", perteneciente a Lingüistica general (1979): ${ }^{19}$

Como después de las grandes tormentas

un mar

que es sólo una parte del mar

rumoroso retrocede

18 Un arte: "El arte de perder se domina fácilmente; / tantas cosas parecen decididas a extraviarse / que su pérdida no es ningún desastre. // Pierde algo cada día. Acepta la angustia / de las llaves perdidas, de las horas derrochadas en vano. / El arte de perder se domina fácilmente. // Después entrénate en perder más lejos, en perder más rápido: / lugares y nombres, los sitios a los que pensabas viajar. / Ninguna de esas pérdidas ocasionará el desastre. // Perdí el reloj de mi madre. Y mira, se me fue / la última o la penúltima de mis tres casas amadas. / El arte de perder se domina fácilmente. // Perdí dos ciudades, dos hermosas ciudades. Y aún más: / algunos reinos que tenía, dos ríos, un continente. / Los extraño, pero no fue un desastre. //Incluso al perderte (la voz bromista, el gesto que amo) no habré mentido. Es indudable /que el arte de perder se domina fácilmente, / así parezca (¡escríbelo!) un desastre.” Traducción de Andrea Garcés. Publicado en El Malpensante.

19 Por supuesto, la comparación es habitual en la producción lírica de los distintos Romanticismos europeos, pero también aparece como clave de lectura (el cuadro dentro del cuadro) en la pintura de género holandesa. Y es que la metáfora remite a la antigüedad griega: “[...] si en la épica arcaica se mostraba el amor como un impacto, un golpe dentro del hombre, parece lógico que su consecuencia sea su concepción como movimiento violento, a partir de la que se documenta una metáfora literaria en el corpus theognideum, presente, como veremos, también en la poesía mélica, mediante la que se concibe el sentimiento como una fuerza que agita al enamorado. [...]. Sobre esta realidad conceptual se crea la metáfora literaria que identifica el deseo con un temporal o una tormenta y la satisfacción del mismo

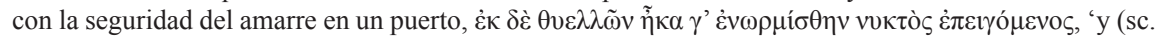
una vez obtenidos los favores del amado), ansioso en la noche amarré lejos de las tormentas" (Hualde Pascual 29). 
y busca en las islas de tierras blancas

y en las huidizas colonias de cetáceos

los lechos abandonados en la fuga,

en la estación de los sueños

yo abandono el lecho de tus manos

para volver,

llena de carcasas y maderas,

de piedras

de metales

y del olor antiguo de otras ciudades.

Navegar es necesario,

vivir no. ${ }^{20}$ (Poesía 377 )

No obstante, si algún tema "nuevo" aparece en el universo perirossiano en esta peculiar narración autobiográfica es la penuria económica en la vejez. Así, hacia el cierre del relato, alude no sin cierta sorna a la falta de recursos como una constante en su devenir vital, y sin embudos nos habla de la necesidad de tener dinero para (sobre) vivir. $^{21}$

El excipit de "Detente, instante, eres tan bello" culmina con una especie de conclusión que retoma con humor la conocida historia de Peri Rossi y su tío afrancesado, poseedor de la primera biblioteca que ella de nena devoró; el mismo que le advirtió que las mujeres no escriben y las que lo hacen terminan suicidándose:

Todavía amo escribir. A pesar de la espalda muy dolorida (una escoliosis desmesurada, tres vértebras y el sacro rotos: dos accidentes en pocos años) y de que quizás, si no se publicara un solo libro más en el mundo, la cultura no perdería mucho. La misión acaba solo con la muerte, igual que el placer. Y de estas dos cosas se trata. He llegado a los setenta y cuatro años sin suicidarme (aunque lo haya deseado y pensado algunas veces, pero qué ser humano no lo ha hecho) a pesar de escribir muchos libros (algunos publicados, otros no) y creo que después de los sesenta y cinco años, el suicidio es eutanasia, de modo que le demostré a mi tío que a veces las mujeres escriben, y a pesar de eso, no se suicidan. (34)

${ }^{20}$ De nuevo una cita en la que resuena toda la literatura occidental: "Navigare necesse est. Vivere non est necesse", atribuida a los Argonautas griegos comandados por Jasón, también al general romano Pompeyo, según Plutarco; que recuperara después Gabrielle D’Annunzio y hasta el propio Fernando de Pessoa en su conocida máxima "Navegar é preciso; viver não é preciso", y que aterriza como leitmotiv de la obra perirrossiana, para ser rescrita en otras claves y en cuerpos-corpus otros.

${ }^{21}$ Remito a la cita referida en el primer apartado de este artículo, donde la autora uruguaya se refiere sin disimulos a la pobreza que sigue acompañándola y de la que, a su edad, puede empezar a padecer serias consecuencias sobre su salud y su calidad de vida ("Detente, instante" 34 ).

$1] 1 \frac{\text { Revista Iberoamericana, Vol. LXXXV, Núm. 268, Julio-Septiembre 2019, }}{1161-778}$ 
La autora afirma y confirma que la literatura sigue siendo su casa $-\mathrm{y}$ que probablemente constituirá su ataúd-, la ironía es manifiesta cuando, como venganza avalada por el tiempo, desmonta el vaticinio de su tío advirtiendo que a su edad el suicidio ya es eutanasia.

El texto termina, curiosamente, con unas palabras prestadas, la dedicatoria del escritor de origen armenio William Saroyan a Carol, su reiterado amor, y que proviene -aunque Peri Rossi no lo explicite- de Nena querida. El fragmento es hermoso: "las cosas que digo en este librito no serían las que yo te diría en definitiva, pero que este sea el primero entre los muchos dones del amor: un presente hecho de todo cuanto yo era en años ya remotos, antes de conocerte" (34). Y así concluye "Detente, instante, eres tan bello".

CierRe INCONCLUSO O DE CÓMO LA AUTORA IMPLÍCITA ME BURLÓ

Como he apuntado antes, Peri Rossi no dice explícitamente que esta dedicatoria pertenece al volumen Nena querida y, como exige la labor de investigar, yo - que no conocía la cita- traté de descubrir en qué libro estaba y qué clave podía suponer el hecho de que "Detente, instante, eres tan bello", el primer artículo autobiográfico de Cristina Peri Rossi, se clausurara con estas palabras prestadas. El libro de relatos de Saroyan cuenta con una traducción al español publicada en Barcelona por la editorial Lauro en 1946 (que bien podía estar en la biblioteca del tío de la escritora) y, además, la editorial Laia, que Peri Rossi dirigió durante un tiempo, publicó el libro de Saroyan en 1989. Los datos cuadraban.

Lo que yo no podía imaginar es que en mi pesquisa iba a encontrar otro primer texto autobiográfico de Cristina Peri Rossi (y ya van tres, como mínimo), concretamente el primer capítulo de una novela autobiográfica inédita que lleva por título -parece ser, precisamente-Nena querida, que se publicó en la revista Malabia, en febrero de $2007 .{ }^{22}$

Lo he leído, Peri Rossi usa hábilmente el hilo conductor de la dedicatoria de Saroyan para hablar sobre todo del amor, con una ciclicidad mucho más cómplice que rutinaria. El texto me gusta, salvo que confieso que me da rabia filológica cuando Peri Rossi describe cómo era el libro de Saroyan que (en efecto) estaba en la biblioteca de su tío y (en efecto) era de 1946, pero ni la portada ni la editorial concuerdan con la de Lauro: Peri Rossi dice que era de Plaza Janés y le atribuye unos colores que a mí no me salen hasta la colección de obras completas que esta editorial barcelonesa empieza a publicar en la década de los sesenta (Nena querida pertenece al volumen de 1962), cuando la autora ya se encontraba en España.

22 Según se recoge en http://letranias.blogspot.com.es/2007/10/cristina-peri-rossi_30.html

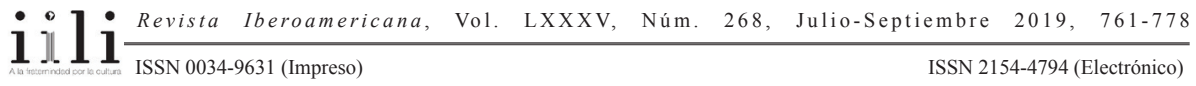


Dolorida y sonriente, como me vaticinaba el correo de Peri Rossi, aprendo la lección y me resisto a que la pura biografía pueda más que la imaginación. Cierro mi cuadernito de documentar verdades, disfruto de la lectura del "nuevo" texto (que es anterior y siempre el primer relato autobiográfico de esta autora implícita en tránsito constante) y me aplico el cuento cuando leo: "Puse a secar el papel. Sin embargo, las letras -los recuerdos- habían desaparecido para siempre. Y yo era la testigo de ese crimen, de ese acto fallido, de ese puente roto, de esa falsa comunicación. Comprendí, súbitamente, la esencia de los malentendidos que constituyen la trama de la vida y de las novelas".

Con toda seguridad también de las autobiografías, y, por supuesto, de los diálogos que se establecen entre autorxs implícitxs y quienes nos dedicamos a asediarlos, críticos implícitos, puede que cómplices presuntamente implicados. Aunque de todo eso haya salido este artículo, tal vez hasta un poco autobiográfico.

\section{Bibliografía}

Alberca, Manuel. El pacto ambiguo. De la novela autobiográfica a la autoficción. Madrid: Biblioteca Nueva, 2007.

Bishop, Elizabeth. "Un arte”. El malpensante. Traducción de Andrea Garcés. $<$ elmalpensante.com/articulo/2402/un_arte>.

Booth, Wayne C. La retórica de la ficción. Trad. Santiago Nogués. Ed. Antoni Bosch. Barcelona, [1961] 1974.

Casas, Ana, comp. La autoficción. Reflexiones teóricas. Madrid: Arco Libros, 2012.

Darrieussecq, Marie. "L'autofiction: un genre pas sérieux". Poétique, 107 (1996): 369-380.

Derrida, Jacques. “The Law of Genre”. Critical Inquiry 7, n. 1 (1980): 55-81. https:// doi.org/10.1086/448088.

Genette, Gérard. Fiction et diction. París: Seuil, 2004.

Gómez de Tejada, Jesús, coord. Erotismo, transgresión y exilio: las voces de Cristina Peri Rossi. Sevilla: Universidad de Sevilla, 2017.

Heinich, Nathalie. De la visibilité. Excellence et singularité en régime médiatique. París: Gallimard, 2012.

Hualde Pascual, Pilar. "Metáforas del amor en la poesía de la Grecia antigua (I): la épica y la lírica arcaicas". Cuadernos de filología clásica: Estudios griegos e indoeuropeos, 26 (2016): 17-47. http://dx.doi.org/10.5209/rev_CFCG.2016. v26.52243.

Moszczynska-Dürst, Katarzyna y Meri Torras Francés. "'Manuel ya es uno de tus primos': Julio Cortázar y Cristina Peri Rossi en clave transcultural”. Ed. Roland Spiller. Julio Cortázar y Adolfo Bioy Casares. Relecturas entrecruzadas. Berlín: Erich Schmidt Verlag, 2016. 139-150.

$111 \frac{\text { Revista Iberoamericana, Vol. LXXXV, Núm. 268, Julio-Septiembre 2019, }}{1161-778}$ 
Peri Rossi, Cristina. "Detente, instante, eres tan bello". Coord. Jesús Gómez de Tejada. 2017. 21-34.

Las replicantes. Palencia: Cálamo, 2016.

Los amores equivocados. Palencia: Menos cuarto-Cálamo, 2015. Julio Cortázar y Cris. Palencia: Cálamo, 2014.

La noche y su artificio. Palencia: Cálamo, 2014.

Habitación de hotel. Barcelona: Plaza \& Janés, 2007.

Poesía reunida. Barcelona: Lumen, 2005.

Estado de exilio. Madrid: Visor, 2003.

Julio Cortázar. Barcelona: Omega, 2001.

Toro, Vera, Sabine Schlickers y Ana Luengo. "Introducción. La auto(r)ficción: modelizaciones, problemas, estado de la investigación". La obsesión del yo. La auto(r)ficción en la literatura española y latinoamericana. Madrid-Frankfurt: Iberoamericana-Vervuert, 2010. 7-29.

Torras Francés, Meri. "Trabajos de amor (re)vividos. Afectos y efectos en Los amores equivocados (2015)". Coord. Jesús Gómez de Tejada. Erotismo, transgresión y exilio: las voces de Cristina Peri Rossi. Sevilla: Universidad de Sevilla, 2017. 259-280.

"La invención de quien en verdad fui. Propuestas de lectura de la autografía de Silvina Ocampo". Eds. Gloria Hintze y María Antonia Zandanel. Género y memoria en América Latina. Mendoza: Qellqasca, 2007. 33-51.

Soy como consiga que me imaginéis. La construcción de la subjetividad en las autobiografías de Gertrudis Gómez de Avellaneda y Sor Juana Inés de la Cruz,. Cádiz: Prensas de la Universidad de Cádiz, 2003.

Trevisan, Graciela. "Estado de Exilio: entrevista con Cristina Peri Rossi”. El tecolote. 21 abr. 2010. $<$ http://eltecolote.org/content/es/arte-cultura/estado-de-exilio-entrevistacon-cristina-peri-rossi-2>. oct. 2017.

Palabras clave: autorrepresentación, autobiografía, autor implicado, memoria

Recibido: diciembre 2017

Aprobado: diciembre 2018

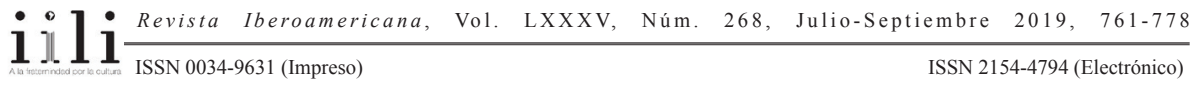

